\title{
Beckwith-Wiedemann syndrome: a quantitative, immunohistochemical study of pancreatic islet cell populations
}

\author{
Y.Stefan ${ }^{1}$, C. Bordi ${ }^{2}$, S. Grasso ${ }^{3}$ and L.Orci ${ }^{1}$ \\ 'Institute of Histology and Embryology, University of Geneva Medical School, Geneva, Switzerland, \\ ${ }^{2}$ Istituto di Anatomia ed Istologia Patologica, Università di Parma, Parma and \\ ${ }^{3}$ Istituto di Anatomia ed Istologia Patologica, Università di Catania, Catania, Italy
}

\begin{abstract}
Summary. The endocrine cell content of the pancreas of two cases of Beckwith-Wiedemann syndrome with islet cell adenomatosis were studied. Insulin, glucagon, somatostatin and pancreatic polypeptide cells were evaluated qualitatively and quantitatively with the indirect immunofluorescence method and morphometry was used to establish the volume density of the four endocrine cell populations. This evaluation showed a marked increase of insulin and glucagon cells and a lesser augmentation of pancreatic polypeptide cells and somatostatin cells. However, the percent of somatostatin cells was decreased in comparison with controls. Qualitatively, the two pancreas were characterized by the lack of segregation of glucagon and pancreatic polypeptide cells to distinct parts of the gland, with each cell type being abundant in the pancreatic region in which they are normally very sparse. The marked in-
\end{abstract}

crease of endocrine cells often took the form of giant islet-like structures formed by smaller subunits; however, despite this increase, the distribution of insulin cells respected the normal pattern, i.e. clusters of B cells surrounded by non-B cells. These findings indicate that besides the proliferation of pancreatic endocrine cells maintaining a normal topographical distribution of $B$ versus non- $B$ cells, the pancreas of patients with the Beckwith-Wiedemann syndrome may have undergone abnormal development with a consequent lack of segregation of glucagon and pancreatic polypeptide cells to different parts of the gland.

Key words: Pancreas, endocrine cells, morphometry, development, Beckwith-Wiedemann syndrome, immunofluorescence, pancreatic hormones.
Beckwith [1] and Wiedemann [2] independently described a congenital syndrome characterized by omphalocele, macroglossia, gigantism, hyperplastic visceromegaly, Leydig cell hyperplasia, and cytomegaly of the adrenal cortex. A number of other defects including persistent nephrogenic activity and/or medullary dysplasia of the kidneys and hypoglycaemia were further reported [3]. Subsequent studies showed that these abnormalities occur in various combinations, resulting in complete or incomplete forms of the syndrome [4]. The Beckwith-Wiedemann (BW) syndrome was also shown to be associated with a high incidence of benign and malignant tumours [4].

Hyperinsulinaemic hypoglycaemia is a major clinical problem in most newborns affected by the BW syndrome. The islet cell abnormality responsible for the inappropriate insulin release in BW syndrome, usually referred to as islet cell hyperplasia, is not specific to this syndrome except that the degree of proliferation attained in this condition is particularly marked [5] and has permitted the identification of previously unrecognized cases of the syndrome. Nesidioblastosis was fre- quently used to describe persistent hyperinsulinaemic hypoglycaemia of newborns [5, 6]. However, nesidioblastosis-like histological images are also found in normoglycaemic newborns $[7,8]$ and this term will not be mentioned in the present context.

In the following report, we present a qualitative and quantitative immunohistochemical investigation on the pancreatic endocrine cell content of two cases of BW syndrome associated with massive islet cell proliferation (islet cell adenomatosis).

\section{Subjects and methods}

Case 1 was a full-term female newborn (weight at birth: $3100 \mathrm{~g}$ ) brought to the hospital at day 1 with respiratory distress. On admission, moderate macroglossia and muscle hypotonia were observed. A marked hypoglycaemia was present (Fig. 1) which was not relieved by continuous intravenous glucose infusion ( $5 \%$ solution). Hypoglycaemia was partially corrected by administration of Diazoxide $(3 \times 8$, 10 , then $12 \mathrm{mg} /$ day) from day 3 on, but unstable blood glucose levels persisted (Fig. 1). Serum insulin was determined on day 14 during an oral glucose tolerance test $(1 \mathrm{~g} / \mathrm{kg})$ performed 30 min after cessation of the intravenous glucose infusion. Insulinaemia was $42 \mu \mathrm{U} / \mathrm{ml}$ at 
time 0 and reached a plateau of $130 \mu \mathrm{U} / \mathrm{ml}$ from 30 to $60 \mathrm{~min}$. Death occurred at day 49 from intractable heart failure.

Post-mortem examination revealed pancreatomegaly and bilateral cysts (up to $1.5 \mathrm{~cm}$ in diameter) of the adrenals; the weight (in g) of various organs was as follows (the numbers in parentheses are mean organ weight for female infants aged 2 mo [9]): pancreas 13.7 (7.1); adrenals 7.9 (4.7); kidneys 42 (36.0); spleen 18.2 (14.0); liver 154.2 (159.0); lungs 56.6 (74.0). Major histologic findings were diffuse islet cell adenomatosis of the pancreas and persistent nephrogenic activity (nephroblastomatosis) of the subcapsular renal tissue. These findings were consistent with an incomplete form of BW syndrome [4].

Case 2 was a male stillborn following a 35-week pregnancy. Macroglossia, omphalocele, visceromegaly, renal dysplasia, cortical adrenal cytomegaly and Leydig cell hyperplasia, together with pancreatic cell adenomatosis, were indicative of a complete form of BW syndrome [4]. Because of the stillbirth, no laboratory values were available for this case.

The entire pancreas of Case 1 and a complete slice of the pancreas (comprising head, body and tail) of Case 2 were studied. Following paraffin embedding, the fixed samples were cut in 5-um thick serial sections which were processed by the indirect immunofluorescence method for identification of insulin, glucagon, somatostatin and PP cells as previously detailed $[10,11]$. The quantitative evaluation of the four immunofluorescent cell populations was carried out as described $[10,11]$ and the results compared with those from a previously published pool of age-matched, control newborns [11].

\section{Results}

\section{Qualitative}

The islets of Langerhans in the two pancreas studied appeared abnormally large and confluent, resulting often in the formation of "macroislets" formed by smaller subunits (Figs. 2 and 3). These large islets occupied most of the central region of the pancreatic lobules leaving only a narrow rim of acinar tissue; on occasion, the entire lobule consisted of endocrine tissue. Despite this massive increase in the number of endocrine cells (islet cell adenomatosis), the smaller subunits as well as the "macroislets" retained the typical distribution of normal islets, i. e. centrally-located insulin cells surrounded by glucagon, somatostatin and/or pancreatic polypeptide cells. Bipolar islets were also frequently encountered. As detailed previously by immunofluorescence [12], such islets presented all insulin cells concentrated on one side, while glucagon, somatostatin and pancreatic polypeptide cells were on the other pole. Unlike the latter study, however, where bipolar islets have been found in the glucagon-rich lobules only, BW pancreases contained bipolar islets throughout the gland. Another important difference with respect to controls was the fact that the PP-rich lobules in both BW pancreases were present not only in the posterior part of the head, but were observable in various pancreatic regions. In the two cases studied, the extremity of the pancreatic tail was nearly entirely formed by pancreatic polypeptide-rich lobules. Furthermore, islets with numerous pancreatic polypeptide cells also contained abundant glucagon cells.
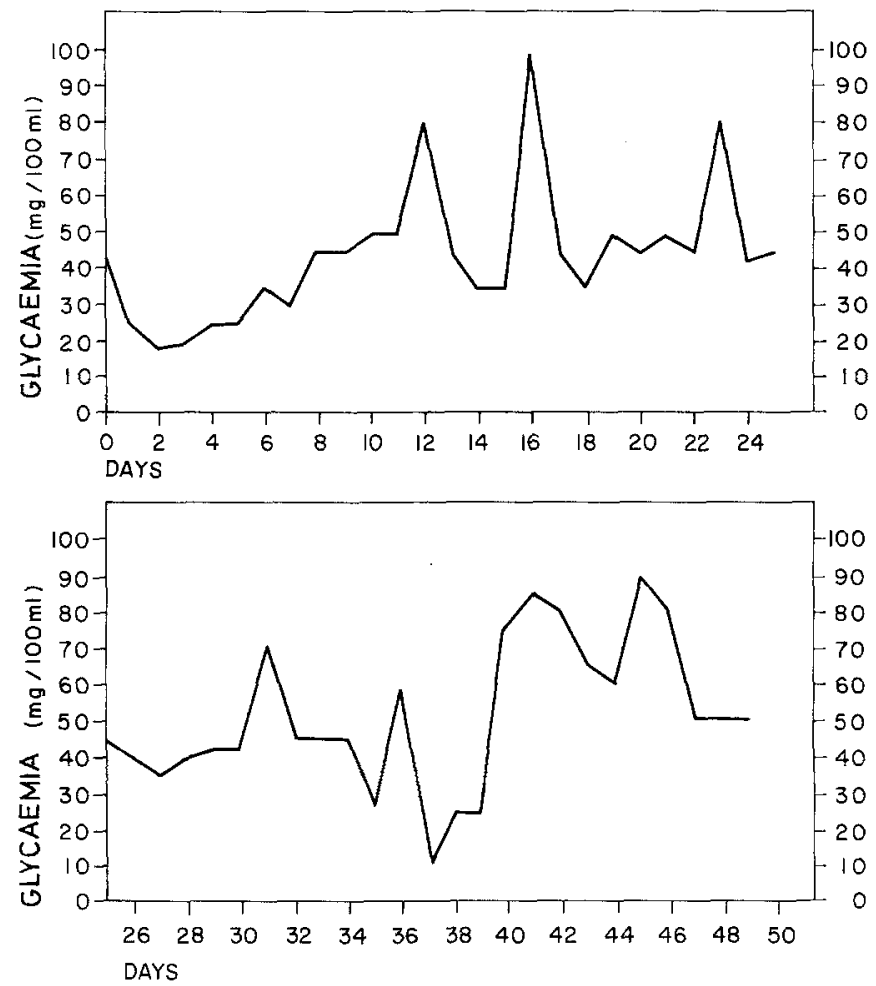

Fig. 1. Graphic representation of the glycaemia of Case 1. From day 1 to day 49 , a continuous infusion of $5 \%$ glucose was given, with the exception of the 2-h glucose tolerance test carried out on day 14. From day 3 to day $5,3 \times 8 \mathrm{mg} /$ day of diazoxide were infused, from day 6 to day $31,3 \times 10 \mathrm{mg} /$ day and from day 32 to day $49,3 \times 12 \mathrm{mg} /$ day

\section{Quantitative}

The volume density $(\mathrm{Vv})$ of the four endocrine cell types in the entire pancreas compared to a pool of 4 agematched controls is presented in Table 1 . Since glucagon cells were abundant in all lobules, irrespective of the high or low pancreatic polypeptide cell content of the latter, the usual delimitation of the pancreas into PPrich lobules and glucagon-rich lobules [11] could not be maintained for the BW pancreas. The delimitation of the pancreas into PP-rich and PP-poor lobules was made instead. In PP-rich lobules, the Vv of insulin cells was increased 18 times for Case 1 and 11 times for Case 2 as compared to the pool [11] of age-matched controls. In PP-poor lobules the increase was 10 and 5 times respectively. Glucagon cells were increased 25 (Case 1) and 40 (Case 2) times in PP-rich lobules, while the increase was 4 and 8 times in PP-poor lobules. The $\mathrm{Vv}$ of somatostatin cells was only slightly increased in both cases and this was translated into a marked decrease of the percentage of this cell type when compared to that of controls. The volume density of pancreatic polypeptide cells was also not markedly increased; this overall limited increase of the $\mathrm{Vv}$ of pancreatic polypeptide cells resulted in a decrease of their percentage, as compared to controls, in PP-rich lobules, but in a marked augmentation of the percentage in PP-poor lob- 

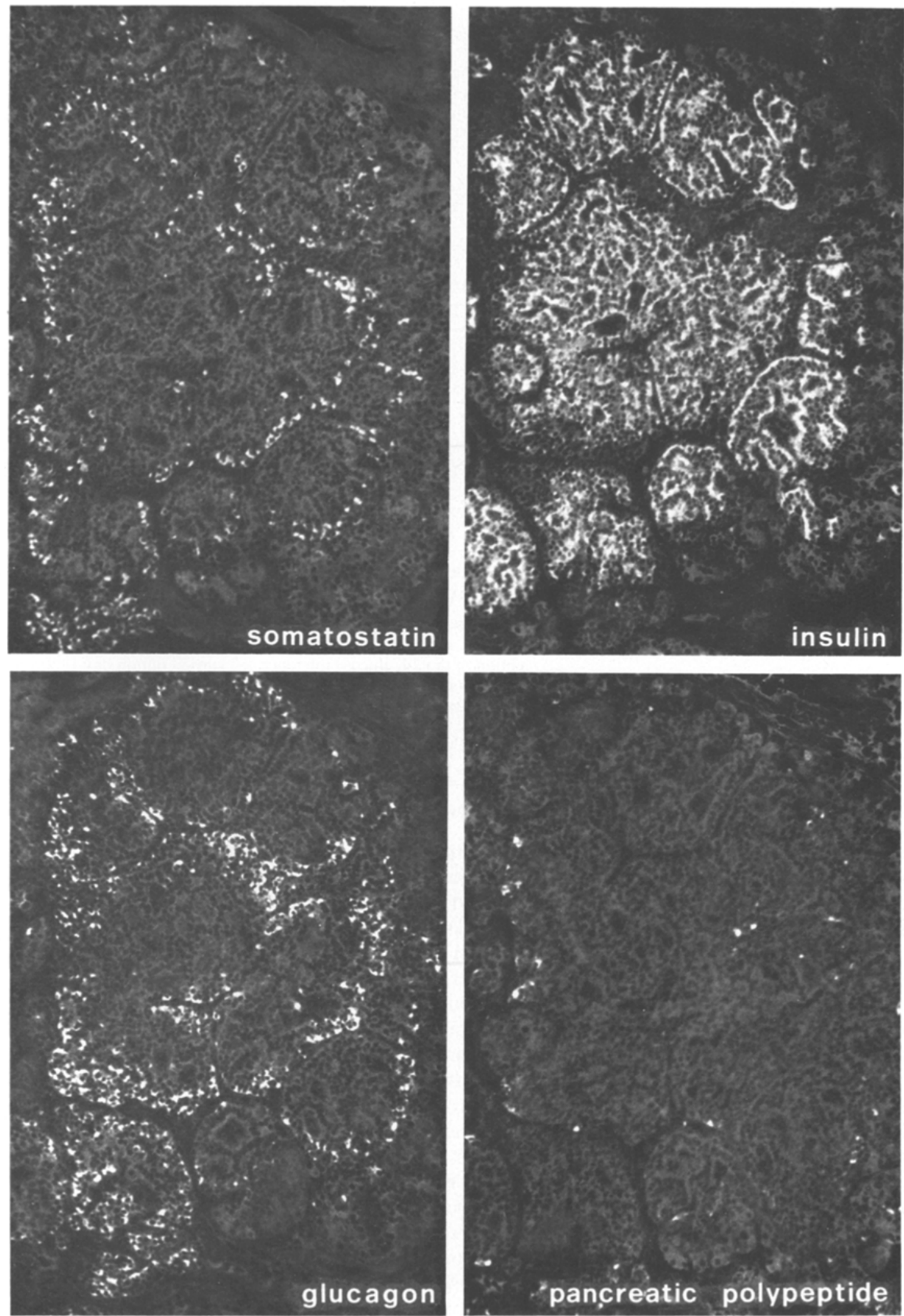

Fig. 2. Series of four successive serial sections of a BW pancreas (Case 1) immunostained with somatostatin, insulin, glucagon and pancreatic polypeptide antisera respectively. PP-poor lobule. The abundant insulin immunofluorescence takes the appearance of a "macroislet" formed by the confluence of several smaller subunits. The confluence of subunits is also evidenced by the distribution of somatostatin and glucagon cells which appear as crescents and/or incomplete rings delimiting the periphery of the insulin cell cluster. $(\times 180)$ 

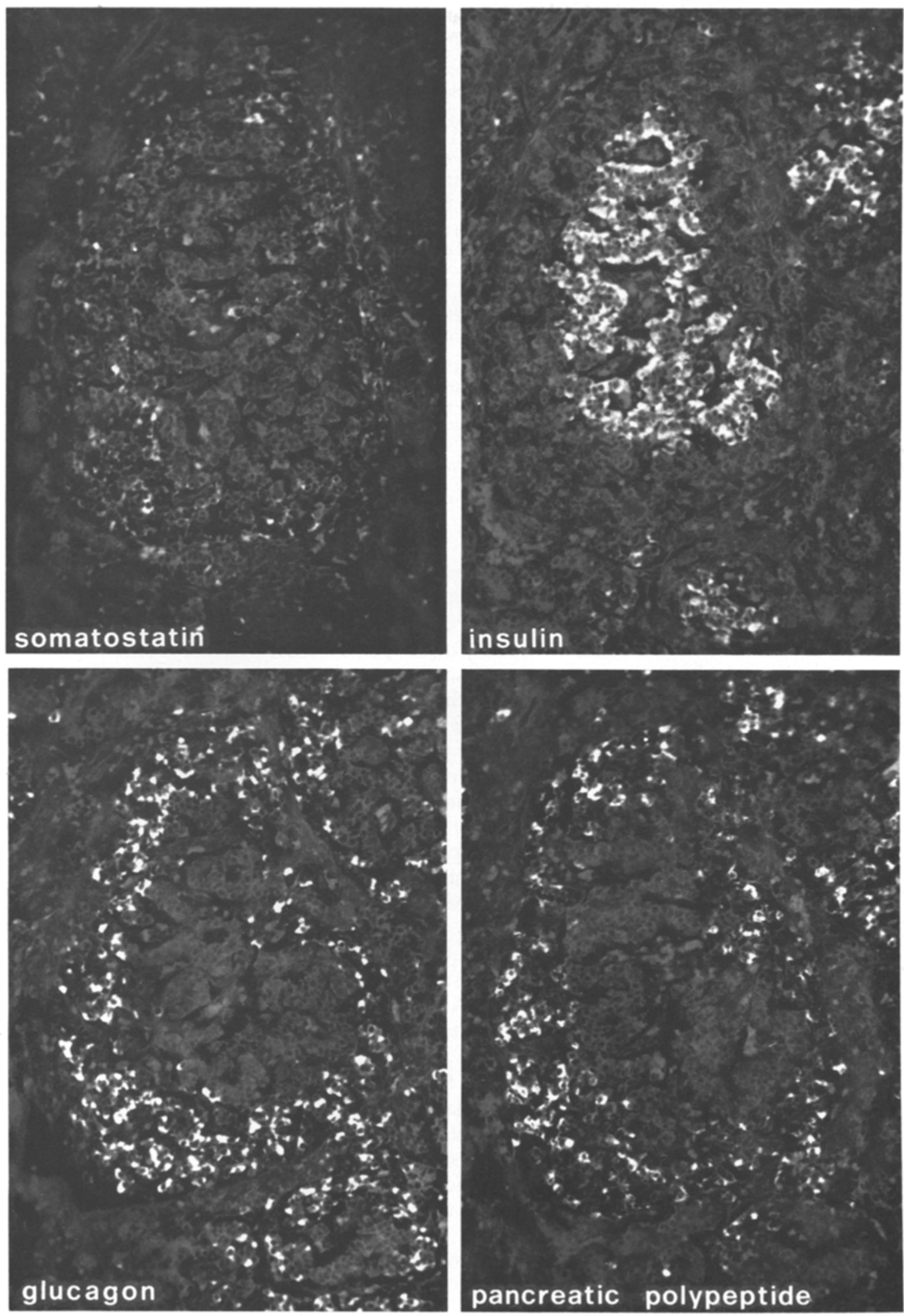

Fig. 3. Series of four successive serial sections of a BW pancreas (Case 2) immunostained with somatostatin, insulin, glucagon and pancreatic polypeptide antisera respectively. PP-rich lobule. Insulin immunofluorescence reveals a large cluster of positive cells and two smaller subunits. Glucagon and PP cell immunostaining delimits a rim formed of abundant cells of each type surrounding the insulin cell mass. Somatostatin cells are relatively sparse. $(\times 180)$ 
Table 1. Quantitative evaluation of the immunofluorescent endocrine cell populations in the pancreas of newborns affected with the BeckwithWiedemann $(\mathrm{BW})$ syndrome. $\mathrm{VV}=$ volume density $\left(\times 10^{3}\right)$ determined by morphometry [11]; \%= percentage of volume density of entire endocrine tissue; $\mu \mathrm{I}=$ total volume in microliters [11]

\begin{tabular}{|c|c|c|c|c|c|c|c|c|c|c|c|c|}
\hline & \multicolumn{3}{|l|}{ Insulin } & \multicolumn{3}{|l|}{ Glucagon } & \multicolumn{3}{|l|}{ Somatostatin } & \multicolumn{3}{|c|}{ Pancreatic polypeptide } \\
\hline \multicolumn{13}{|c|}{ PP-rich lobules } \\
\hline Controls ${ }^{1}$ & $9.64 \pm 3.19$ & 31.2 & 3.0 & $0.39 \pm 0.15$ & 1.3 & 0.2 & $5.33 \pm 1.61$ & 17.2 & 1.7 & $15.54 \pm 4.52$ & 50.3 & 5.0 \\
\hline BW 2 & 88.21 & 44.3 & - & 44.65 & 22.4 & - & 17.55 & 8.8 & - & 48.83 & 24.5 & - \\
\hline \multicolumn{13}{|c|}{ PP-poor lobules $^{2}$} \\
\hline BW1 & 183.17 & 80.2 & 856.5 & 22.24 & 9.8 & 105.1 & 20.44 & 8.9 & 96.6 & 2.62 & 1.1 & 12.4 \\
\hline Controls $^{1}$ & $16.80 \pm 3.63$ & 53.6 & 59.0 & $4.44 \pm 0.68$ & 14.2 & 14.0 & $10.04 \pm 1.42$ & 32.0 & 31.1 & $0.08 \pm 0.04$ & 0.3 & 0.3 \\
\hline BW 2 & 102.32 & 62.1 & - & 46.85 & 28.4 & - & 15.29 & 9.3 & - & 0.34 & 0.2 & - \\
\hline Controls $^{1}$ & $19.55 \pm 1.66$ & 43.3 & - & $8.94 \pm 1.10$ & 19.8 & - & $16.52 \pm 0.61$ & 36.6 & - & $0.16 \pm 0.05$ & 0.4 & - \\
\hline
\end{tabular}

The controls for BW 1 and BW 2 cases, respectively, were the pooled values ( $n=4$, means \pm SEM) from four age-matched infants [11]: 0-3 days

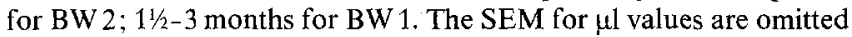

2 The usual delimitation of the pancreas into PP-rich and glucagon-rich lobules [11] could not be maintained for the BW pancreas since glucagon cells were abundant in all lobules

ules. The absolute volume $(\mu 1)$ of each of the four endocrine cell types, which could be determined in Case 1 since the total pancreatic weight was available, showed a 25 times increase above controls for insulin cells, a 10 times increase of glucagon cells and a 20 times augmentation for pancreatic polypeptide cells; the latter increase was due to the fact that these cells were abundant, unlike in controls, throughout the pancreas and not in the PP-rich region only. Somatostatin cells were increased 6 times.

\section{Discussion}

The above-described qualitative and quantitative results have identified, in two cases of Beckwith-Wiedemann syndrome, a massive proliferation of pancreatic endocrine cell types in all pancreatic regions consistent with a generalized islet cell adenomatosis in the classification proposed by Jaffe et al. [7]. This proliferation presented two interesting features: on the one hand, it respected the normal topographical distribution of $B$ cells versus non-B cells, the latter appearing always situated at the periphery of insulin cell clusters; on the other hand, the pancreas of both BW syndromes was characterized by the disorganization of the regional glucagon/pancreatic polypeptide cell distribution. In normal pancreas, lobules rich in pancreatic polypeptide cells and lobules rich in glucagon cells are segregated to different regions of the gland: PP-rich lobules are restricted in the posterior area of the head [13], while glucagon-rich lobules are concentrated in the anterior part of the head and in the entire body and tail. This was in marked contrast with the BW pancreas, where PP-rich lobules appeared scattered throughout the gland and contained a sizable number of glucagon cells. The in- homogeneous distribution of glucagon and pancreatic polypeptide cells in ventral and dorsal pancreatic regions is considered to originate in the dual mode of formation of the pancreas during embryogenesis [13-15]; the present observation suggests, therefore, a perturbation of the pancreatic development in BW syndrome. A recent investigation [8] compared the volume density of the four pancreatic endocrine cell types in the pancreas of hyperinsulinaemic hypoglycaemic infants with that of normoglycaemic controls. This study showed no statistically significant difference for insulin and glucagon cells between the two groups. The massive increase in insulin and glucagon cells characterizing our cases of $\mathrm{BW}$ syndrome, together with the defect in glucagon and PP-cells segregation to distinct pancreatic regions, suggests that this syndrome is a separate entity of neonatal hyperinsulinaemic hypoglycaemia and islet cell hyperplasia. A final note of caution is in order concerning the interpretation of our immunocytochemical data with respect to the possible physiopathology of the hypoglycaemia. Bright cellular fluorescence which is quantitated implies well granulated cells; the amount of degranulated cells cannot be ascertained by our immunofluorescent standards although such cells could nevertheless be actively secreting and contributing to the altered hormonal balance.

Acknowledgements. We thank Drs. B. Gaillard and J.Cox for providing us the pancreatic slice of Case 2 . Supported by the Swiss National Science Foundation, grant no. 3.460.83.

\section{References}

1. Beckwith JB (1963) Extreme cytomegaly of the adrenal fetal cortex, omphalocele, hyperplasia of kidneys and pancreas and Leydig cell hyperplasia: another syndrome? Annual Meeting of the 
Western Society of Pediatric Research, Los Angeles, Calif 11 Nov 1963

2. Wiedemann HR (1964) Complexe malformatif familial avec hernie ombilicale et macroglossie. Un "syndrome nouveau"? J Genet Hum 13: 223-232

3. Filippi G, McKusick VA (1970) The Beckwith-Wiedemann syndrome (the exomphalos-macroglossia-gigantism syndrome). Report of two cases and review of the literature. Medicine 49: 279-298

4. Sotelo-Avila C, Gonzalez-Crussi F, Fowler JW (1980) Complete and incomplete forms of Beckwith-Wiedemann syndrome: their oncogenic potential. J Pediatr 96: 47-50

5. Dahms BB, Landing BH, Blaskovics M, Roe TF (1980) Nesidioblastosis and other islet cell abnormalities in hyperinsulinemic hypoglycemia of childhood. Hum Pathol 11: 641-649

6. Heitz. PU, Klöppel G, Häcki WH, Polak JM, Pearse AGE (1977) Nesidioblastosis: the pathologic basis of persistent hyperinsulinaemic hypoglycaemia in infants. Diabetes 26: 632-642

7. Jaffe R, Hashida Y, Yunis EJ (1980) Pancreatic pathology in hyperinsulinemic hypoglycemia of infancy. Lab Invest 42: 356-365

8. Rahier J, Fält K, Müntefering H, Becker K, Gepts W, Falkmer S (1984) The basic structural lesion of persistent neonatal hypoglycaemia with hyperinsulinism: deficiency of pancreatic D cells or hyperactivity of B cells? Diabetologia 26: 282-289

9. Schulz DM, Giordano DA, Schulz DH (1962) Weights of organs of fetuses and infants. Arch Pathol 74: 244-250

10. Stefan Y, Orci L, Malaisse-Lagae F, Perrelet A, Patel Y, Unger RH (1982) Quantitation of endocrine cell content in the pancreas of nondiabetic and diabetic humans. Diabetes 31: 694-700
11. Stefan Y, Grasso S, Perrelet A, Orci L (1983) A quantitative immunofluorescence study of the endocrine cell populations in the developing human pancreas. Diabetes 32: 293-301

12. Orci L, Stefan Y, Bonner-Weir S, Perrelet A, Unger R (1981) "Obligatory" association between A- and D-cells demonstrated by bipolar islets in neonatal pancreas. Diabetologia 21: 73-74

13. Malaisse-Lagae F, Stefan Y, Cox J, Perrelet A, Orci L (1979) Identification of a lobe in the adult human pancreas rich in pancreatic polypeptide. Diabetologia 17: 361-365

14. Stefan Y, Grasso S, Perrelet A, Orci L (1982) The pancreatic polypeptide-rich lobe of the human pancreas: definitive identification of its derivation from the ventral pancreatic primordium. Diabetologia 23: $141-142$

15. Rahier J, Wallon J, Gepts W, Haot J (1979) Localization of pancreatic polypeptide cells in a limited lobe of the human pancreas: remnant of the ventral primordium? Cell Tiss Res 200:359-366

Received: 25 May 1985

and in revised form: 30 September 1985

Dr. L. Orci

Institute of Histology and Embryology

University of Geneva Medical School

1 , rue Michel Servet

CH-1211 Geneva 4

Switzerland 